\title{
The determinants of pharmaceutical research and development expenditures
}

\author{
Henry Grabowski, John Vernon \\ Department of Economics, Duke University, Durham, NC 27708, USA \\ (e-mail: grabow@econ.duke.edu)
}

\begin{abstract}
Since the late 1970s, pharmaceutical R\&D has grown at a rapid rate relative to sales and other variables. In this paper, we examine the determinants of pharmaceutical R\&D using a pooled data sample of 11 major drug firms over the period 1974 to 1994. We find that expected returns and cash flows are important explanatory variables of firm research intensities during this period. This is consistent with our results for an earlier sample period characterized by very different growth patterns on R\&D.
\end{abstract}

Key words: Pharmaceuticals $-R \& D$ - Innovation - Cash flow - Expected returns

JEL-classification: L65, O31, O33

\section{Introduction}

In an earlier paper, we examined the determinants of pharmaceutical R\&D outlays in the United States for the period spanning the early 1960s through the mid 1970s (Grabowski and Vernon, 1981). This period was characterized by a dramatic decline in new drug introductions together with relatively stagnant growth in R\&D expenditures. The drug industry was adjusting to increased regulatory controls and other factors during this time. In our regression analyses, we found that lagged returns on R\&D and cash flow availability were important determinants of R\&D investment

Paper presented at the 1998 World Conference of the International Joseph A. Schumpeter Society, Vienna, June 13-16, 1998.

Correspondence to: $\mathrm{H}$. Grabowski 
behavior. In particular, we found that lagged $R \& D$ returns exhibited a significant downward overall trend during this period and this, in turn, exerted an important restraining effect on R\&D investment outlays.

In this paper, we examine the determinants of pharmaceutical $R \& D$ for the more recent time period 1974 to 1994. In contrast with the earlier one, this period has been characterized by a rapid growth in industry R\&D expenditures. Since the late 1970s, R\&D expenditures have grown at more than $10 \%$ annually in real terms (PhRMA, 1997). Furthermore, R\&Dto-sales percentages have increased by several percentage points. We wish to examine the factors underlying these dramatic changes in $R \& D$ investment behavior. For this purpose, we utilize an analytical model with the same basic structure as the one employed in our earlier paper.

The plan of the paper is as follows. In the next section, we review past work, together with recent trends and developments. The following sections present our model and the empirical findings. The final section considers policy implications and discusses important issues for continuing academic research.

\section{Evolution of pharmaceutical R\&D: prior work and current trends}

\subsection{The post-1962 period}

In our earlier paper, we examined the determinants of firm research intensities (R\&D-to-sales ratios) for a pooled sample of ten drug firms over the period 1962-1975. This was a period in which firm research intensities exhibited a moderately declining overall trend. This was in contrast to the earlier post-World War II period in which firm research intensities were expanding over time.

A major event in 1962 was the passage of Kefauver-Harris Amendments to the Food, Drug and Cosmetic Act. This occurred in the aftermath of the Thalidomide incident. ${ }^{1}$ This 1962 law created the investigational new drug (IND) process and the requirement that all new drugs demonstrate proof of efficacy as well as safety before FDA approval (Wardell and Lasagna, 1975). The FDA took several years to implement fully all of the changes from the 1962 law. Several academic studies were performed analyzing industry development times and R\&D costs during this period. They found that development times increased by several years after 1962, and R\&D costs per new drug introduction also increased several fold (Baily, 1972; Wardell and Lasagna, 1975).

A key determinant of research intensities in our model is the expected return on $R \& D$. With $R \& D$ times and costs per NCE rising significantly during the post- 62 period, it is plausible to postulate the returns on $R \& D$ would be falling. In our earlier analysis of R\&D determinants, we utilized a proxy measure of the expected returns on R\&D. The numerator of this measure was a firm's sales of its recent new drug introductions and the

\footnotetext{
${ }^{1}$ Thalidomide was a drug which produced fetal deformities in pregnant women. It had been introduced in several European countries but not in the US.
} 


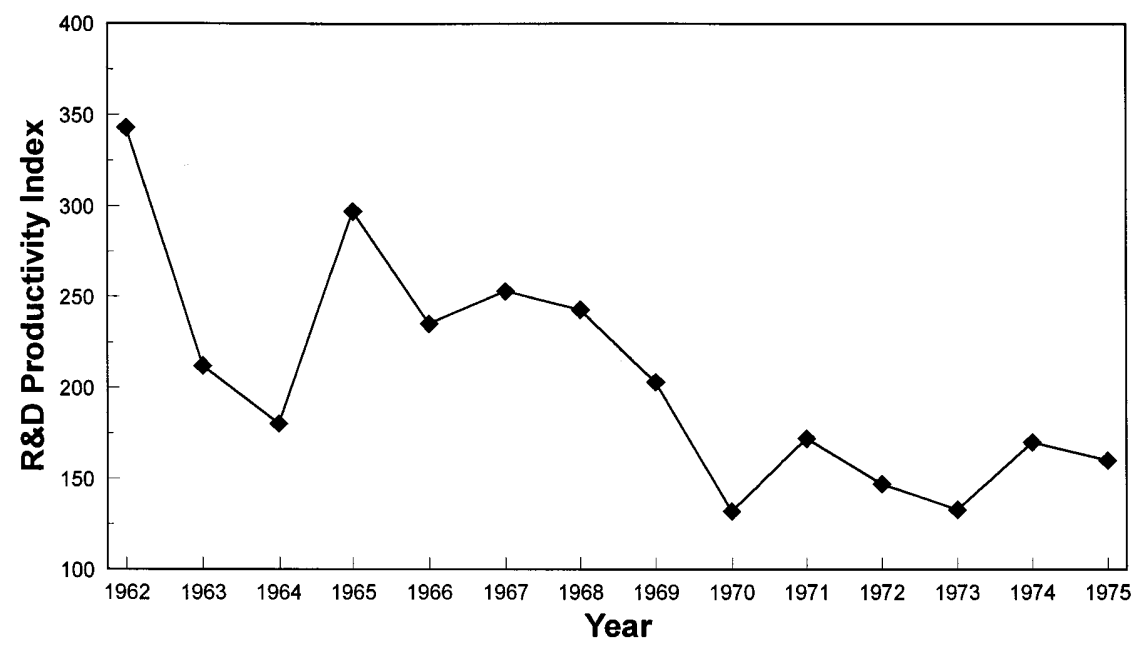

Fig. 1. Aggregate R\&D Productivity Index, 1962-1975

denominator was its lagged $R \& D$ expenditures. We labeled this as an $R \& D$ productivity index.

Figure 1 shows a plot of the aggregate trend in the R\&D productivity index variable for the ten firms in our sample over the period 1962-1975. It indicates that new product sales per R\&D investment dollar fell rather significantly during this period. This pattern of declining returns is consistent with the finding of several other studies for the post-62 period (see for example, Baily, 1972; Schwartzman, 1976).

The other major explanatory variable of $\mathrm{R} \& \mathrm{D}$ in our earlier work was the availability of cash flows. We found that cash flows remained relatively stable relative to overall sales over most of the post-62 period. This expanding supply of internally generated funds helped to buffer the observed decline in R\&D intensities. However, as the lower returns on the new drug introductions cumulated over time, cash flow margins were also starting to be affected adversely. By the early 1970s many major drug successes of the earlier post-war era were also coming off patent and subject to increasing competitive pressures.

In subsequent work, we analyzed the distribution of returns on new drug introductions in the 1970s and 1980s (Grabowski and Vernon, 1990, 1994). We found that this distribution is highly skewed. ${ }^{2}$ In particular, a small number of drugs in the right hand tail of the distribution have a disproportionate effect on the mean returns realized by particular firms and the industry as a whole in any period. These top decile drugs are often referred to in the industry as "blockbusters," and the search for them is a key driver of the R\&D process.

The period between the end of World War II and the early 1960s saw the introduction of many important advances that were also big winners from

\footnotetext{
${ }^{2}$ This skewness of returns is a characteristic of returns distribution in several other research-intensive industries (Scherer, 1998).
} 
an economic perspective. There were many significant new antibiotic drugs, but this period also witnessed the introduction of hydrocortisone and several other corticoids, the thiazide diuretic drugs, major and minor tranquilizers, and the initial birth control products (Pharmacy Times, 1976).

After the passage of the 1962 Amendments, the industry was faced not only with adjusting to more stringent regulatory requirements, but also the prospect of diminished technological opportunities in many of therapeutic classes that had previously experienced major advances. There were certainly important drug innovations in the post-62 period, most notably the first cephalosporin antibiotics in 1964 and the introduction of the beta blockers in 1968 (Wardell and Lasagna, 1975). ${ }^{3}$ However, the main approach to drug R\&D in this era was random screening of candidates. The ability to find new drugs that were advances over established ones became increasingly harder and costlier in many therapeutic classes.

The first half of the 1970s was characterized by fewer major new drugs, and a decline in the mean returns to R\&D (Grabowski and Vernon, 1990). The leading firms began to focus their R\&D activities on new therapeutic targets and approaches. As the 1970s progressed, it was clear that the industry was facing a crossroads with respect to its $R \& D$ performance. Some observers saw the drug industry as perhaps entering a period of technological maturity (Scherer, 1978).

\subsection{Drug innovation since 1975}

The period of the late 1970s represented a turning point with respect to the innovative performance of the industry. In particular, an important milestone was the introduction of Tagamet (cimetidine) by SmithKline. This drug not only represented a major advance in the treatment of ulcers but also was seen as an important validation of the emerging "rational drug design" approach to drug discovery and development. In particular, the Tagamet molecule was designed to block specific cell receptors (histamine $\mathrm{H}_{2}$ receptors) known to affect the process of acid secretion. Tagamet was the first of the histamine $\mathrm{H}_{2}$ receptor inhibitors, and it yielded high private and social returns (Geweke and Weisbrod, 1981; Grabowski and Vernon, 1990). By 1980, it had become the largest selling drug worldwide. It was replaced as the top-ranked selling drug by Zantac in 1987, another $\mathrm{H}_{2}$ blocker that claimed certain advantages relative to Tagamet in terms of drug interactions and dosage convenience.

The new rational drug design approach and expanding disease targets produced many new drugs that could be classified as both major therapeutic and economic successes. Table 1 provides a list of significant compounds

\footnotetext{
${ }^{3}$ The adverse effects of increased US regulatory controls during this period are illustrated by the differential behavior of US and UK regulatory authorities toward propranolol (Inderal), the first of the beta blockers class. This compound was initially approved in the UK in 1965 with indications for hypertension, angina and arrhythmias. It was approved 2.5 years later in the United States, but only for the very narrow indication of arrhythmias (Wardell and Lasagna, 1975). It was not until July 1976 that it was approved in the United States for hypertension, the indication with the largest number of patients.
} 
Table 1. Significant drug innovations, 1978-1994

\begin{tabular}{llll}
\hline Year & New drug & Primary use & Mode of action \\
\hline 1978 & Tagamet & Ulcers & H$_{2}$ receptor antagonist \\
1981 & Capoten & Hypertension & ACE inhibitor \\
1982 & Zovirax & Herpes Virus & Nucleoside \\
1982 & Procardia & Hypertension & Calcium channel blocker \\
1983 & Sandimmune & Transplantation & Interleukin-2 inhibitor \\
1984 & Augmentin & Antibiotic & Beta lactam inhibitor \\
1985 & Seldane & Allergies & H receptor antagonist \\
1986 & Cipro & Antibiotic & DNA gyrase inhibitor \\
1987 & Mevacor & Cholesterol reduction & HMG-C A reductase inhibitor \\
1987 & Retrovir & AIDS & Nucleoside/RT inhibitor \\
1988 & Prozac & Depression & Serotonin Re-uptake inhibitor \\
1989 & Epogen & Anemia & Erythrocyte growth factor \\
1989 & Prilosec & Ulcers & Proton pump inhibitor \\
1990 & Diflucan & Antifungal & Structural inhibitor \\
1990 & Clozaril & Schizophrenia & Atypical tricyclic \\
1991 & Biaxin & Antibiotic & Protein synthesis inhibitor \\
1991 & Zofran & Nausea/vomiting & 5Ht3 antagonist \\
1991 & Neupogen & Cancer adjunct & Neutrophil growth factor \\
1993 & Taxol & Ovarian cancer & Anti-microtubule \\
1993 & Imitrex & Migraine & 5HT1 agonist \\
1994 & Risperdal & Schizophrenia & D2/5HT2 antagonists \\
\hline
\end{tabular}

introduced between 1978 and 1994. The drugs on this list represent a new mode of action for treating particular diseases. They were also major commercial successes, given that they all achieved global peak sales of at least one half billion dollars (measured in 1998 dollars). The primary indications for these drugs include many categories which previously had little or no adequate drug treatments (herpes, transplantation, AIDS, migraine headaches, schizophrenia, etc.). Other drugs in this table provided benefits in terms of better side effect profiles and patient tolerability for the treatment of widespread medical problems (i.e., hypertension, cholesterol reduction, depression, etc.).

In most cases, the drugs listed in Table 1 were the first movers in a new chemical family of drug products (Green, 1998). Competition in these classes center around new product introductions and is subject to both incremental and generational advances over time. Many follow-on introductions in a new class also achieve sales in the top deciles of the returns distribution. Indeed, while strong first-mover advantages exist in pharmaceuticals, the second or third introduction in a class sometimes overtakes the pioneering one as the drug of choice. ${ }^{4}$

It is clear that the past two decades have witnessed an impressive renaissance in drug innovation and R\&D competition that was very broad in its scope. The main hypothesis of the present paper is that R\&D intensities in pharmaceuticals have increased over time because major new drug introductions have generated favorable expected returns to R\&D investment,

\footnotetext{
${ }^{4}$ For analyses of competition in two major therapeutic classes, see Suslow (1996) and Ellison et al. (1997).
} 


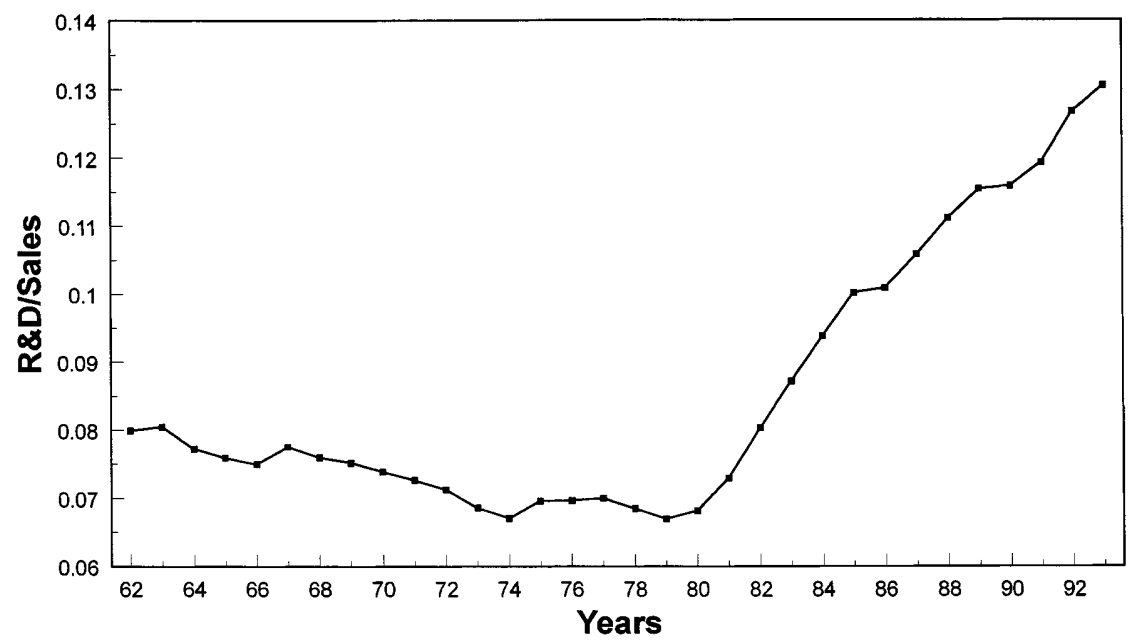

Fig. 2. Aggregate R\&D/Sales, 1962-1993

and expanding industry cash flows have provided a readily available (and relatively low cost) source of funds to finance $R \& D$. This will be examined in terms of a regression model that is discussed in the next section.

The dramatic changes in research intensities that have occurred over time in this industry are illustrated in Fig. 2. This shows the trend in the aggregate R\&D-to-sales ratios for seven firms that reported R\&D data over the full 33-year period, 1962 to $1993 .{ }^{5}$ This graph shows that R\&D intensity was generally declining in the period 1962 to 1974 , that it stabilized in the 1975 to 1980 period, and it has increased almost in a linear fashion since 1980. The value achieved in 1993 is close to double what it was at the minimal point in 1974. We will examine the determinants of firm R\&D intensities for the 1974 to 1994 period using an economic model that is similar in structure to our earlier work.

\section{The R\&D investment decision}

In accordance with basic economic theory, the R\&D investment decision is determined by the intersection of the marginal rate of return on investment schedule (mrr) and the marginal cost of capital schedule (mcc). The mrr schedule is obtained by arranging potential R\&D projects in order of decreasing rates of return, and the mcc schedule reflects the opportunity cost of alternative investments for the firm.

Figure 3 shows the determination of the optimal amount of investment, $\mathrm{R}^{*}$. The mcc schedule here consists of two horizontal segments, representing a lower cost of internal funds and a higher cost of new equity financing, and

\footnotetext{
${ }^{5}$ The seven firms are Abbott, Bristol Myers, Lilly, Merck, Pfizer, Schering Plough and Upjohn. They are the seven firms common to our prior and current regression analyses (as discussed in Section 4).
} 


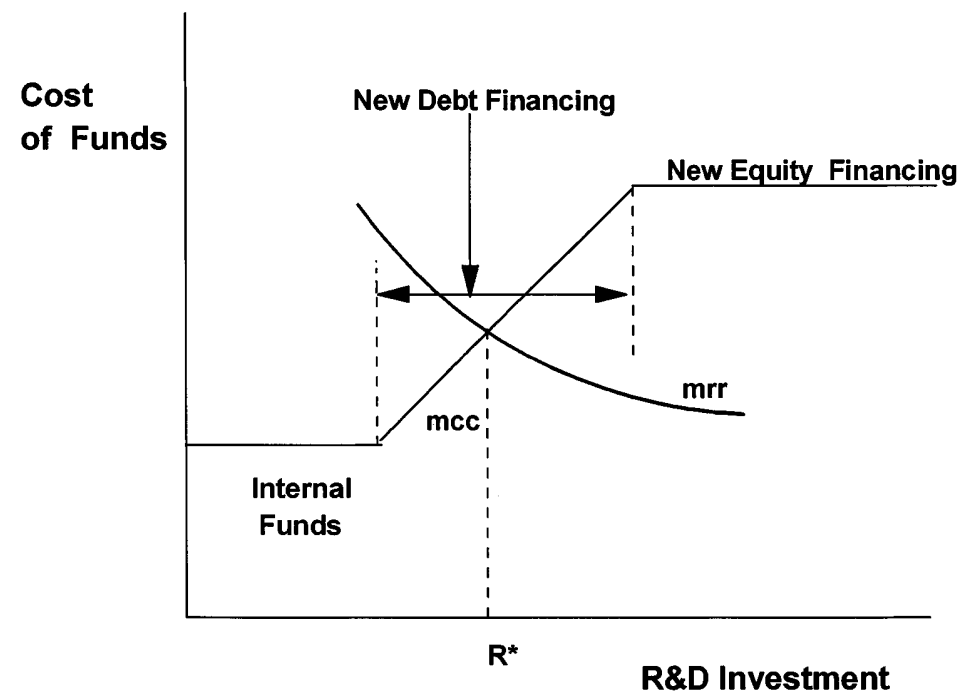

Fig. 3. The R\&D investment decision

a rising connecting segment that represents the cost of new debt financing. Recent work on firm investment behavior supports the hypothesis shown here that the cost of internal funds is less than that for new debt and equity financing. There have been many theoretical reasons given for the difference in the cost of internal and external funds. They include transaction costs, tax advantage, agency problems, costs of financial distress, and asymmetric information (for a recent survey, see Hubbard, 1998).

In the pharmaceutical industry, the problems of great uncertainty about the outcome of $R \& D$, the length of the R\&D process (12-14 years), and asymmetric information combine to make the difference between internal and external funds especially important. In addition, unlike fixed investment in plant and equipment, the outcome of drug $R \& D$ is simply new knowledge, which may or may not have value. ${ }^{6}$

Algebraically, the optimal level of investment, $\mathrm{R}^{*}$, is obtained by solving the equation,

$$
\operatorname{mrr}(\mathrm{R}, \mathrm{X})=\operatorname{mcc}(\mathrm{R}, \mathrm{Z})
$$

where $\mathrm{R}=$ investment expenditures in $\mathrm{R} \& \mathrm{D} ; \mathrm{X}=\mathrm{a}$ vector of variables influencing the return from new drug $R \& D$; and $Z=$ a vector of variables

\footnotetext{
${ }^{6}$ The extremely difficult problem of raising funds for R\&D in small biotech firms with little or no cash flow highlights this point. The head of one such biotech firm indicated that in order to obtain venture capital, a new project must have the ability to generate a 25-35 percent annual rate of return (US House of Representatives Hearings, 1995). In addition, suppliers of venture capital must see a viable exit strategy for getting their money out of the company - that is, through an initial public offering, a merger, or a corporate partnership with an established company. Many such corporate partnerships are now taking place in the industry where established companies with large cash flows supply funds to small biotech firms.
} 


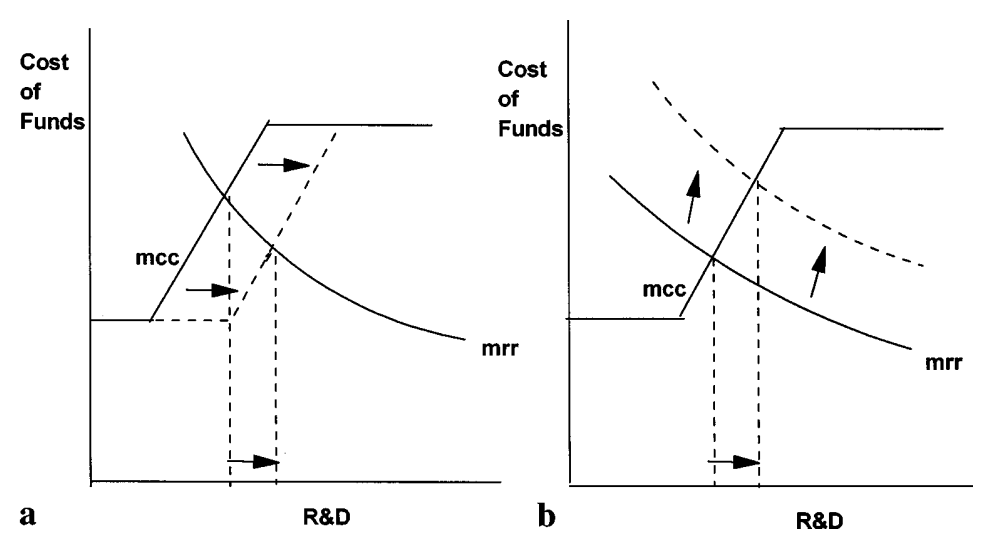

Fig. 4a, b. Two effects on R\&D investment. a Increased cash flow. b Increased expected returns

influencing the opportunity cost of investing in new drug R\&D. The reduced form solution is therefore,

$$
\mathrm{R}^{*}=\mathrm{f}(\mathrm{X}, \mathrm{Z}) \text {. }
$$

This is the basic equation that will be estimated in the regression analysis to be described in the next section.

Figure 4 provides a simple graphical analysis of the two major determinants of R\&D investment that we have found in our earlier work, and that we also find in the current study. First, in Fig. 4a we show that increased availability of internal funds, or cash flow, leads to a positive effect on optimal R\&D investment. Second, in Fig. 4b, we show that an increase in expected returns shifts the mrr schedule upward and also leads to a positive effect on optimal R\&D investment.

\section{Regression model}

Data on firm financial variables were obtained from Standard and Poor Compustat files. The data are taken from consolidated income and balance sheet statements which include the firm's total sales and expenditures for all products and services on a global basis. Two major considerations in selecting the sample of firms were the availability of $R \& D$ expenditures for the complete 1974-1994 period and a high degree of specialization in ethical drugs. This led to a sample of eleven firms.?

The eleven firms in our sample accounted for $42.3 \%$ of ethical drug sales in the United States in a middle year of our sample, 1989. Also, for the

\footnotetext{
${ }^{7}$ The eleven firms are Abbott, American Home Products, Bristol Meyers, Johnson \& Johnson, Lilly, Merck, Pfizer, Schering Plough, Syntex, Upjohn, and Warner-Lambert. Seven of these firms were included in our early analysis of R\&D determinants (footnote 4). We excluded three firms from our prior sample due to merger and data consistency problems and added four firms that were not available previously because of incomplete $\mathrm{R} \& \mathrm{D}$ expenditures data.
} 
period 1985-1989, they accounted for just over half of the innovative output of the industry in that period. Innovative output is measured as the sum of the first three years' sales of all new chemical entities (NCEs) introduced in the United States during the period.

Based on the general discussion in the last section, we specify the regression model shown below:

$$
\begin{aligned}
\mathrm{RDS}_{\mathrm{it}}=\mathrm{f}\left(\mathrm{E} \pi_{\mathrm{t}}, \mathrm{CFS}_{\mathrm{it}-1},\right. & \left.\mathrm{D}_{\mathrm{i}}\right) \\
\text { where } \mathrm{RDS}_{\mathrm{it}}= & \mathrm{R} \& \mathrm{D} \text { divided by sales for each firm for each year } \\
\mathrm{E} \pi_{\mathrm{t}}= & \text { index of expected returns to } \\
& \mathrm{R} \& \mathrm{D} \text { in pharmaceuticals in year } \mathrm{t} \\
\mathrm{CFS}_{\mathrm{it}-1}= & \text { cash flow divided by sales } \\
& \text { for each firm in year } \mathrm{t}-1 \\
\mathrm{D}_{\mathrm{i}}= & \text { dummy variable for firm } \mathrm{i}
\end{aligned}
$$

For the $E \pi_{\mathrm{t}}$, variable two measures were used. The first measure is the Newsal variable. It is defined as the total new product sales (first three years) for industry NCEs introduced in years $0,-1,-2,-3$, and -4 , all divided by real $R \& D$ expenditures in year -2 . It is therefore a rough "productivity of R\&D" variable, at the industry level.

The basic idea underlying this formulation is that firms are well aware of the new products being introduced throughout the industry, and that their expectations depend not only on their own recent successes, but also on the success of the industry as a whole. Many firms pursue parallel paths in their R\&D activities, and there are strong spillover opportunities across firms in pharmaceuticals (Henderson and Cockburn, 1996). In addition, competitors are often able to appropriate some of the knowledge from new approaches to drug research and apply them to different medical problems and therapeutic areas. It should be noted that we tried a firm level version of the Newsal variable in early specifications, but perhaps because of its high degree of volatility at the firm level, this formulation was only marginally statistically significant. ${ }^{8}$

Figure 5 shows the plot of the Newsal variable for the sample period. As noted earlier it has a generally rising trend. This is a dramatic contrast to the behavior of the Newsal variable between 1962 and 1974 that exhibited a strong downward trend (Fig. 2).

Because of the obvious difficulty of capturing firms' expected returns through a "past success" variable, we also report the results for a second $\mathrm{E} \pi_{\mathrm{i}}$ variable, Imarg. This is a measure of the industry margin, which is defined as the weighted average of pre-tax profits divided by sales for the pharmaceutical divisions of the eleven drug firms in our sample. Figure 6

\footnotetext{
${ }^{8}$ In our prior study of $\mathrm{R} \& \mathrm{D}$ determinants, this variable was measured at the firm level, and it was significant at normal confidence levels. In this regard, it is relevant to point out that there is evidence that spillovers were more narrow in scope and took longer to realize when the random screening approach to drug discovery was dominant (Sykes, 1997; Henderson and Cockburn, 1996).
} 


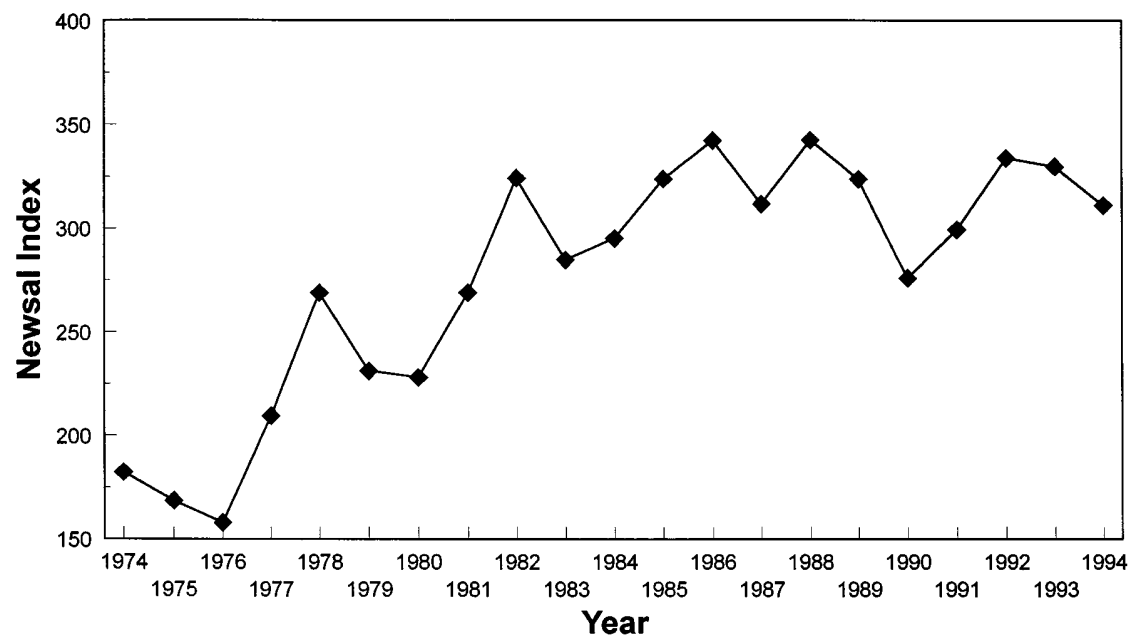

Fig. 5. Newsal Index, 1974-1994

plots the Imarg variable and shows that it was declining during the 1970s and increasing after $1981 .^{9}$

The two variables, Newsal and Imarg, can be viewed as substitutes. However, it is also possible to think of them as capturing different aspects of expected returns to R\&D. That is, Newsal captures the productivity of recent R\&D in terms of the amount of sales of new introductions. On the other hand, Imarg is the profit margin of the industry, and therefore captures the price-cost margin on current sales (i.e., both for new as well as established products). While IMARG is a function of R\&D performance, it also reflects broader economic forces impinging on the industry. For this reason, we report regressions that include both Newsal and Imarg together, and regressions in which each is used alone.

The $\mathrm{CFS}_{\mathrm{it}-1}$ variable is designed to measure the firm's internally generated funds before investment in $\mathrm{R} \& \mathrm{D}$, other capital assets, and before the payment of dividends. It consists of the sum of after-tax income, depreciation, plus after-tax $R \& D . R \& D$ is expensed for tax purposes and receives an implicit subsidy compared to other capital assets. Hence, one must add back "after-tax R\&D outlays" to after-tax income and depreciation to obtain pre-investment cash flows (Hall, 1992; Grabowski and Mueller, 1972). For this purpose, we used a flat tax rate of $33 \%{ }^{10}$

\footnotetext{
${ }^{9}$ As discussed in our earlier study, the declining trend in industry profit margins during the 1970s reflects the fact that drug prices lagged the producer price index substantially during the 1970s, while the reverse was true during the 1980s (Grabowski and Vernon, 1990). An Office of Technology Assessment study (1993) also pointed to increased insurance coverage during the 1980 s as an important factor positively affecting industry sales and profit margins.

10 “After-tax R\&D" is computed as 0.67 times R\&D expenditures. We used 33 percent as the average effective tax for pharmaceutical firms based on the analysis of this issue undertaken in Grabowski and Vernon (1994).
} 


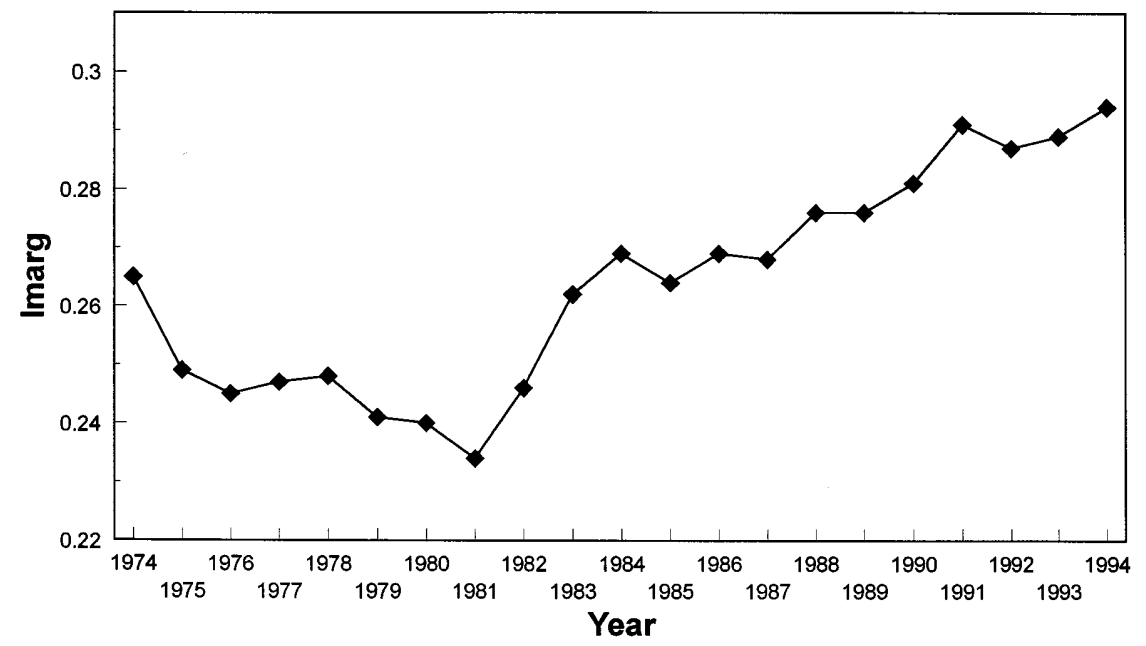

Fig. 6. Imarg, 1974-1994

Theoretically, RDS is a complicated function of all past cash flows. Although we experimented with alternative lag formulations for this variable, the one year lag appeared to perform marginally better in terms of statistical performance. The CFS variable aggregated over all firms is plotted in Fig. 7. Note that it was generally flat until it began to increase in 1983.

Firm dummy variables were introduced for ten of the eleven firms to capture all firm differences between firms and over time. We tested the null hypothesis that the firm dummies were simultaneously all equal, and it was easily rejected. In the regression results, we do not report the coefficients of individual dummy variables.

Two tables of regression equations are reported. Table 2 covers the complete time period of 1974 to 1994 . Table 3, containing the same specifications as Table 1, covers the shorter period 1980 to 1994 . Generally, the equations are quite similar although the t-statistics are slightly lower for the shorter period. Even so, the t-statistics indicate highly significant effects of both expected returns and cash flow variables in all equations. All variables also have the theoretically expected positive algebraic signs.

Equation 1 in Table 2 uses the Newsal version of expected returns, and both Newsal and CFS are highly significant with the expected signs. The coefficient of the cash flow variable, CFS, is 0.31 and can be interpreted as implying that a $\$ 1$ million increase (decrease) in cash flow will lead approximately to a $\$ 310,000$ increase (decrease) in $R \& D$ expenditures. This compares to coefficients of 0.26 in Grabowski's 1968 study and a range of $0.22-0.27$ in our 1981 study. On the other hand, when we turn to equations 2 and 3 , the coefficients are much lower, equal to 0.12 and 0.13 respectively. These comparisons are summarized in Table 4.

Inclusion of both Newsal and Imarg in equation 2 seems to support the idea that they do capture somewhat different aspects of expected returns, as discussed earlier. When Imarg is included in equations 2 and 3, however, 


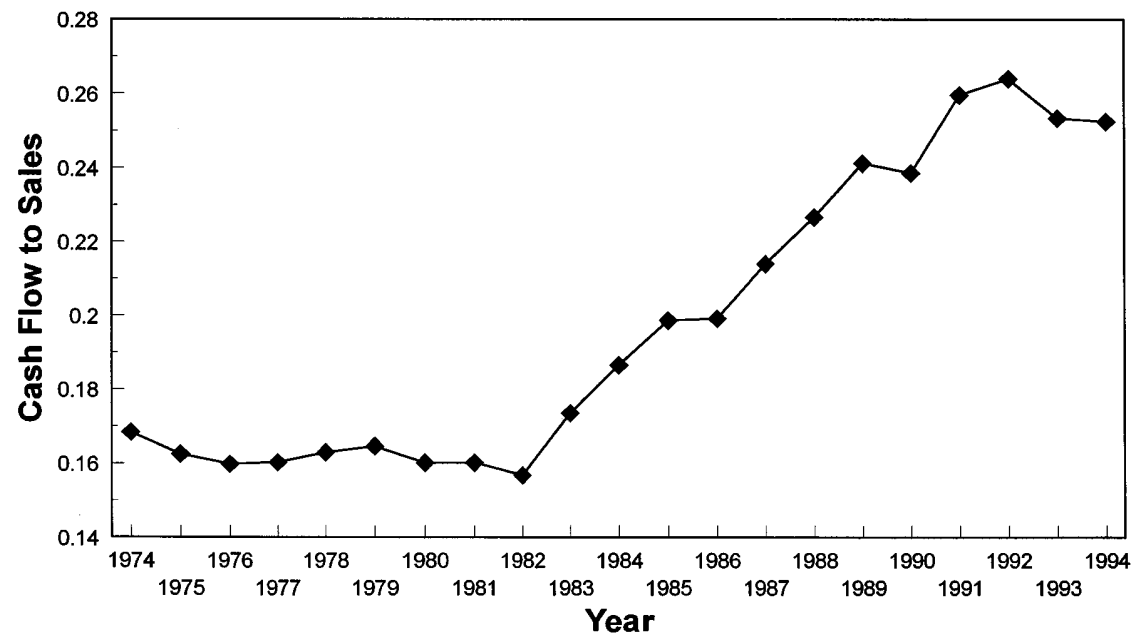

Fig. 7. Cash flow to sales, 1974-1994

Table 2. Linear regression explaining R\&D-to-sales ratio for eleven firms, 1974-1994

\begin{tabular}{llcc}
\hline Equation $^{\mathrm{a}}$ & 1 & 2 & 3 \\
\hline Intercept & $-0.03(6.46)$ & $-0.19(12.40)$ & $-0.21(12.47)$ \\
Newsal & $0.19(10.42)$ & $0.12(7.81)$ & - \\
Imarg & - & $0.73(10.59)$ & $0.94(12.98)$ \\
$\mathrm{CFS}$ & $0.31(13.73)$ & $0.12(4.74)$ & $0.13(4.61)$ \\
Rsq/F & $0.87 / 124.5$ & $0.91 / 182.4$ & $0.89 / 150.8$ \\
$\mathrm{~N}$ & 230 & 230 & 230 \\
\hline
\end{tabular}

${ }^{a}$ Firm dummies also included in these equations.

Table 3. Linear regression explaining R\&D-to-sales ratio for eleven firms, 1980-1994

\begin{tabular}{lccc}
\hline Equation $^{\mathrm{a}}$ & 1 & 2 & 3 \\
\hline Intercept & $-0.04(3.35)$ & $-0.18(10.32)$ & $-0.18(10.02)$ \\
Newsal & $0.20(5.45)$ & $0.08(2.49)$ & - \\
Imarg & - & $0.77(9.47)$ & $0.85(11.24)$ \\
CFS & $0.32(13.41)$ & $0.12(4.14)$ & $0.11(3.89)$ \\
Rsq $/ \mathrm{F}$ & $0.87 / 91.48$ & $0.92 / 141.0$ & $0.92 / 147.16$ \\
$\mathrm{~N}$ & 164 & 164 & 164 \\
\hline
\end{tabular}

${ }^{a}$ Firm dummies also included in these equations.

the coefficients of CFS fall in magnitude and have lower t-statistics than when only Newsal is included (in equation 1). This is probably due to the higher correlation between Imarg and CFS ( $\mathrm{r}=0.51)$ than between Newsal and CFS ( $\mathrm{r}=0.33)$, as would be expected given their definitions.

To summarize the findings, there is strong evidence that both expected return and cash flow variables are important determinant factors for 
Table 4. Cash flow and drug R\&D consistency of estimates over time

\begin{tabular}{lll}
\hline Study & Period & Coefficient $^{\mathrm{a}}$ \\
\hline Grabowski (JPE 1968) & $1958-62$ & 0.26 \\
Grabowski and Vernon (AEI 1981) & $1962-75$ & $0.22-0.27$ \\
Grabowski and Vernon (1998) & $1974-94$ & $0.12-0.31$ \\
\hline
\end{tabular}

${ }^{a}$ Variable has somewhat different definitions and lag structures in prior studies.

pharmaceutical R\&D. However, it is difficult to untangle the two effects in a precise fashion from econometric analyses. This is consistent with analyses of R\&D determinants performed on broad cross-sectional data samples (Hall, 1992; Grabowski and Mueller, 1972).

\section{Policy implications and future research issues}

The empirical analysis undertaken in this paper indicates that expected returns and cash flow are important determinants of pharmaceutical R\&D. The rapid growth in the R\&D intensities of drug firms since the late seventies reflects the strong positive effects of both of these factors. These findings are in accordance with the model illustrated in Figs. 2 and 3. The results are also consistent with our earlier analysis that focused on a period of declining rather than rising research intensities.

The analysis has a number of important applications. In particular, it provides a conceptual framework to analyze the effects of proposed policy actions on pharmaceutical R\&D. Government interventions affect R\&D returns and the supply of funds to undertake pharmaceutical $R \& D$ in a multitude of ways. These include pre-market regulatory controls, drug price and reimbursement controls, product formularies, tax policy, patents, technology transfer policies, etc. (Towse, 1995). It is important to gauge the effects of these different government policies on drug industry R\&D, given the evidence from medical and econometric studies that drug innovations have yielded high social returns (see, for example, Lichtenberg, 1998; Cutler et al., 1997).

One example of how this general framework can be utilized to study R\&D impacts is our recent analysis of the Vaccines For Children Program (Grabowski and Vernon, 1997). In 1993 the Clinton Administration created this Program to increase the government's purchases of pediatric vaccines. One estimate from the Department of Health and Human Services was that the government would eventually account for approximately $80 \%$ of the US vaccine market purchases at prices significantly below the private sector. Our analysis indicated that if the program were implemented in accordance with these initial plans and projections, it would have had very significant negative impacts on the returns to and the cash flows available for new vaccines. As a consequence, vaccine suppliers would be expected to shift R\&D investments to adult vaccines and other biopharmaceutical $R \& D$ projects.

The most far-reaching government proposal affecting pharmaceuticals in recent years was the 1994 Clinton Health Reform Act. This Act would 
have extended government price controls over a large segment of the U.S. pharmaceutical market. While analyses were commissioned by the Administration concerning its effects on the demand for pharmaceuticals and drug budget implications, the authors of the Act gave little attention to its potential long-run effects on drug R\&D or innovation. A partial analysis of this issue was eventually undertaken by the Congressional Budget Office (CBO, 1994). Given the essential role that R\&D plays in economic growth and welfare, it would seem important that prospective analyses be undertaken of the effects of policy changes on R\&D in this and other researchintense industries.

In this paper, we have focused on the determinants of total R\&D outlays. Other microeconomic issues regarding drug R\&D investment behavior also warrant further academic research. For example, the allocation of R\&D funds between discovery and development activities and across different therapeutic areas remains an important area that has received little formal study. In addition, the multitude of recent $R \& D$ partnership agreements between universities, start-up biotech firms and major pharmaceutical firms raise a number of intriguing issues concerning the future evolution of the pharmaceutical $\mathrm{R} \& \mathrm{D}$ process.

\section{References}

Baily MN (1972) Research and development costs and returns: the U.S. pharmaceutical industry. Journal of Political Economy 80: 70-85

Congressional Budget Office (1994) How health care reform affects pharmaceutical research and development. U.S. Congress, Washington

Cutler D, McClellan M, Newhouse J (1997) The costs and benefits of intensive treatment for cardiovascular disease. AEI/Brookings Institution, Conference on Measuring the Prices of Medical Treatments

Ellison SF, Cockburn I, Grilliches Z and Hausman J (1997) Characteristics of demand for pharmaceutical products: An examination of four cephalosporins. RAND Journal of Economics 28: 426-446

Geweke JF, Weisbrod BA (1981) Some economic consequences of technological advance in medical care: the case of a new drug. In: Helms RB (ed) Drugs and health. AEI Press, Washington

Grabowski HG (1968) The determinants of industrial research and development: a study of the chemical, drug and petroleum industries. Journal of Political Economy 76: 292306

Grabowski HG, Mueller DC (1972) Managerial and stockholder welfare models of firm expenditures. Review of Economics and Statistics 54: 9-24

Grabowski HG, Vernon JM (1981) The determinants of R\&D expenditures. In: Helms RB (ed) Drugs and health. AEI Press, Washington

Grabowski HG, Vernon JM (1990) A new look at the returns and risks to pharmaceutical R\&D. Management Science 36: 804-821

Grabowski HG, Vernon JM (1994) Returns to R\&D on New Drug Introductions in the 1980s. Journal of Health Economics 13: 383-406

Grabowski HG, Vernon JM (1997) The search for new vaccines: the effects of the Vaccines for Children Program. AEI Press, Washington

Green DG (1998) Is price regulation necessary? A summary of arguments. Pharmacoeconomics 14, Supp.1: 137-142

Hall BH (1992) Investment and research and development at the firm level: does the source of financing matter. Working Paper no. 4096, NBER, Cambridge, Mass, June 
Henderson R, Cockburn I (1996) Scale, scope and spillovers: The determinants of research productivity in drug discovery. RAND Journal of Economics 27: 32-59

Hubbard RG (1998) Capital-market imperfections and investment. Journal of Economic Literature 36: 193-225

Lichtenberg FR (1998) Pharmaceutical innovation as a process of creative destruction. Working Paper, Columbia University

Office of Technology Assessment (1993) Pharmaceutical R\&D: Costs, risks and rewards. Congress of the United States, Washington

Pharmacy Times (1976) Compilation of new drugs: 1940 through 1975

PhRMA (1997) 1997 industry profile. Pharmaceutical Research and Manufacturers of America

Schwartzman D (1976) Innovation in the pharmaceutical industry. Johns Hopkins University Press, Baltimore

Scherer FM (1998) The size distribution of profits from innovation. Annales d'Economie et de Statistique

Scherer FM (1978) Technological maturity and waning economic growth. Arts and Science 1: 7-11

Suslow VY (1996) Measuring quality change in the market for anti-ulcer drugs. In: Helms RB (ed) Competitive strategies in the pharmaceutical industry. AEI Press, Washington

Sykes R (1997) The pharmaceutical industry in the new millennium: Capturing the scientific promise. Centre for Medicines Research International Publications, Carshalton, Surrey, UK

Towse A (1995) (ed), Industrial policy and the pharmaceutical industry. Office of Health Economics, London

U.S. House of Representatives (1995) Hearings before the Subcommittee on Health and the Environment

Wardell WW, Lasagna L (1975) Regulation and drug development. AEI Press, Washington 